\title{
Corporate Social and Financial Performance: An Extended Stakeholder Theory, and Empirical Test with Accounting Measures
}

\author{
Gerwin Van der Laan \\ Hans Van Ees \\ Arjen Van Witteloostuijn
}

\begin{abstract}
Although agreement on the positive sign of the relationship between corporate social and financial performance is observed in the literature, the mechanisms that constitute this relationship are not yet well-known. We address this issue by extending management's stakeholder theory by adding insights from psychology's prospect decision theory and sociology's resource dependence theory. Empirically, we analyze an extensive panel dataset, including information on disaggregated measures of social performance for the S\&P 500 in the 1997-2002 period. In so doing, we enrich the extant literature by focusing on stakeholder heterogeneity, perceptional framing, and disaggregated measures of corporate social performance.
\end{abstract}

KEY WORDS: panel data analysis, prospect decision theory, resource dependence theory, social responsibility, stakeholder theory

\section{Introduction}

Three decades of research into the relationship between corporate social performance (CSP) and corporate financial performance (CFP) suggest, by and large, that corporate well-doing enhances firm profitability (Orlitzky et al., 2003). The analyses have remained at a fairly high level of aggregation, giving rise to the criticism that overall measures of CSP and CFP do not take the rich variety of underlying determinants into account (Wood and Jones, 1995). The current study aims to enhance the understanding of the drivers of the relationship between corporate social and financial performance. For one, theoretically, we will develop hypotheses as to the impact on the CSP-CFP relationship of stakeholder heterogeneity and perception biases. Additionally, empirically, we will explore an extensive panel dataset that covers the corporations in the S\&P 500 over the 1997-2002 period, including decomposed information about underlying dimensions of corporate social performance. More specifically, our key contribution is two-fold.

First, we analyze the effect of heterogeneity among corporate stakeholder groups on the CSPCFP nexus, following Clarkson's (1995) distinction between primary or 'private' stakeholders, and secondary or 'public' stakeholders. Wood and Jones (1995) argued that there is a mismatch between the variables in previous research. For instance, employees and Greenpeace put different emphasis on issues of labor conditions and environmental pollution. With this critique in mind, we explicitly incorporate more fine-grained measures of corporate social performance into our analysis. After all, the question as to the relationship between corporate social and financial performance cannot be considered separate from the analysis of how corporations interact with different stakeholder groups that weigh the underlying CSP dimensions differently. Our hypothesis is that secondary stakeholders have to rely on a company's reputation for good CSP more than primary stakeholders, who have comparably direct exchanges with the firm. A CSP reputation should thus be related to CFP for secondary stakeholders more than for primary stakeholders.

We therefore contribute to the literature by showing that fine-grained decomposed measures provide insights into the costs and benefits of 
corporate social performance beyond those that composite measures have demonstrated in previous research. Of course, by way of steppingstone, we only distinguish two larger stakeholder groups primary and secondary ones. Consequently, in future research, efforts to further hypothesize upon lower-level relationships between the satisfaction of specific stakeholder demands (e.g., customers, employees, NGOs and shareholders) and corporate financial performance are required.

Second, we build upon Jawahar and McLaughlin's (2001) model in which prospect theory and the organizational life cycle approach are combined to demonstrate the importance of certain stakeholders in various business environments. We leave the life cycle hypothesis to future research, but take the prospect theoretical arguments from psychology on board. One of prospect decision theory's key predictions is that decision makers' perceptions are biased, implying an asymmetry in how they judge losses versus gains. In this paper's context, following his logic, we argue that the effect on corporate financial performance of bad CSP can be expected to be larger than the impact of good CSP, ceteris paribus, because decision makers evaluate the decision to invest in social performance differently in a situation in which they stand to loose a reputation for being a good corporate citizen as compared to a situation where the company is to decide whether or not to build such a reputation. We show that this is indeed the case for primary stakeholders.

We therefore contribute by pointing out the relevance of the decision maker's perception of the business environment, which we hypothesize to be associated with an important bias in terms of a losses - gains asymmetry. We show that a good reputation for corporate social performance is not simply the mirror image of a reputation for substandard social performance. This builds on Hillman and Keim's (2001) finding that CSP is particularly relevant for primary stakeholders by adding the impact of the decision maker's framing of the business environment.

The organization of this paper is as follows. The next section sets the scene by defining the core concepts of our theory and embedding these in the extant literature. Subsequently, we introduce our hypotheses. After that, we describe data and method. Next, we present our results. Finally, in the concluding section, we offer an appraisal, with special emphasis on future research issues.

\section{Theory development}

\section{Background}

Much of the debate on corporate social performance is of a normative nature, building upon the idea that moral principles should or should not guide corporate decision making. Three constructs have been used throughout the literature to refer to business involvement in social issues. Corporate social responsibility (CSR, or CSR1) refers to the business principles that guide managerial decision making. Corporate social responsiveness (CSR2) is used to describe the processes through which corporations respond, or not do so, to social demands. Several arguments for and against business involvement in social activities have been presented, neatly summarized by Margolis and Walsh (2003). Corporate social performance (CSP), finally, describes the outcomes of socially responsive behavior (Wood 1991a, b). CSP is of primary interest in the present study.

In addition to the mostly normative theories, empirical researchers have produced a more positive approach to issues of corporate social performance by instrumentally addressing the relationship between corporate social and financial performance. In this approach, CSP is seen as instrumental to firm effectiveness, based upon the fundamental assumption that success in business is somehow related to the extent to which the firm manages to deal with the different needs of its direct stakeholders and the wider social environment.

The large body of empirical analyses that explore the relationship between corporate financial and social performance has been reviewed in a number of narrative literature reviews and a meta-analysis (Margolis and Walsh, 2003; Orlitzky et al., 2003; Pava and Krausz, 1996; Wood and Jones, 1995). The narrative literature reviews engage in simple votecounting and present a large number of studies in which a positive relationship between CSP and CFP is supported. For example, Pava and Krausz (1996) review 21 studies that appeared between 1972 and 1992. For 12 of these, a positive relationship was found, whereas in only one case a negative 
relationship was reported. The eight remaining studies showed no significant results. Margolis and Walsh (2003) analyze a larger set of studies (127) and also find many (54) in which the correlation between CSP and CFP is positive, and only a few (7) in which a negative coefficient is reported.

The disadvantage of reviews like these is that they summarize research in which the focus has been on controlling for type-I errors only. The possibility that a relationship is not detected is seldomly addressed in singular empirical analyses. However, a growing body of research suggests that these errors are becoming more and more pressing (Schmidt, 1992). A meta-analysis can control for measurement and sampling error, and Orlitzky et al. (2003) provide such an analysis for the CSP-CFP relationship. In fact, such study artifacts as sampling and measurement error may account for $25 \%-100 \%$ of cross-study variance in their sample of studies. Notwithstanding their improved methodology, they do not draw different conclusions, though: the CSPCFP correlation coefficient tends to remain positive.

Theoretically, however, an abundance of propositions explaining the CSP-CFP nexus at a lower level of aggregation is yet to be expected. Godfrey (2005) develops a set of propositions asserting that good deeds lead to a positive reputation that the firm can subsequently use to achieve financial benefits. Hillman and Keim (2001) propose that there is a relationship between investments in issues with which primary stakeholders are concerned, but that this relationship does not extend to secondary stakeholders' social demands. We extend this reasoning by incorporating the concept of reputation into Hillman and Keim's (2001) argumentation. Specifically, we argue that a reputation for social performance is particularly relevant for secondary stakeholders, who do not have frequent and direct exchange with the firm. Customers, suppliers and other primary stakeholders, on the one hand, can infer the company's involvement in social activities from the terms of their exchanges. Secondary stakeholders, on the other hand, do not have these information sources at their disposal and rely on reputation measures to decide upon the extent to which they support the organization. Consequently, a reputation for CSP is argued to be related to CFP for secondary more than for primary stakeholders. The next section substantiates this argument.
Additionally, we argue that the effect on corporate financial performance of bad CSP can be expected to be larger than the impact of good CSP, ceteris paribus, because decision makers evaluate the decision to invest in social performance differently in a situation in which they stand to loose a reputation for being a good corporate citizen as compared to a situation where the company is to decide whether or not to build such a reputation. Here, we apply insights from psychology's prospect decision theory. Again, we provide more details below.

\section{Stakeholder and resource dependence theories}

The most influential model used for the analysis of corporate social performance is the principles-processes-outcomes model, as formulated by Wood (1991a, b), In this model, processes of social responsiveness are argued to result in outcomes: social impacts, programs and policies. Many studies continue by relating social performance outcomes to financial performance directly. Due to problems of observability, most rely on reputation measures, such as those developed by Kinder Lydenberg and Domini (KLD) or Fortune. However, as is apparent in Godfrey's (2005) arguments as well as Fombrun and Shanley's (1990) study, reputation is not a perfect function of a firm's strategic posture.

Not only can reputations be biased due to some firms being more visible than others and stakeholders misinterpreting corporate signals, but firm's management of a reputation can also lead to serious biases, as is evident from James Westphal and Edward Zajac's symbolic management studies (e.g., Westphal and Zajac, 1994, 1998; Zajac and Westphal, 1995). Since symbolic management is most salient where information assymetries are present, and different stakeholders have different forms of exchange relationships (see below) with the corporation, we argue that there is a relationship between a reputation for corporate social performance and corporate financial performance that differs for various stakeholder groups.

The different intensity of the CSP-CFP link follows from a logic that is central to resource dependence theory (Pfeffer and Salancik, 1978). In order to safeguard against the loss of critical resources, the argument goes, an organization must 
develop tailor-made stakeholder relationships. For instance, a cooptation strategy can be used to tie a critical supplier to the firm by offering the CEO of this supplier a seat in the firm's non-executive board. Casciaro and Piskorski (2005) develop two conditions for such constraint absorption to occur - that is, for the internalization of constraints by a focal firm. If for two parties in a relationship mutual dependence is high and the power difference is low, one of the parties is likely to absorp the demand of the other party (Casciaro and Piskorski, 2005).

The characteristic that distinguishes primary from secondary stakeholders lies in the nature of the relationship with the firm. Primary stakeholders are those who have a reciprocal and direct exchange relationship with the corporation, whereas secondary stakeholders try to influence these exchange relationships much more indirectly. In terms of Casciaro and Piskorski (2005), mutual dependence and a balance of power are typical for a focal firm's relationships with primary stakeholders. For secondary stakeholders, in contrast, the stakeholders depend on the firm for the realization of their goals, but the firm is - by definition - not crucially dependent upon these stakeholder groups. Also, relationships of this sort are typically characterized by an imbalance of power.

Since primary stakeholders are involved in frequent exchanges with the corporation, it is likely that the terms of exchange are written down in explicit contracts (e.g., employees) and/or are developed in more frequent and repeated interaction and implicit contracting (e.g., customers). In other words, by making transactions the firm absorps the constraint/social demand posed to it by the consumer, employee or investor. Corporate opportunistic behavior is restricted by the expectation of the losses that will emerge if this behavior - once detected - kills the exchange relationship: employees will leave, customers will go elsewhere, shareholders will sell their stocks, et cetera. Hence, the importance of a good relationship with primary stakeholders tends to be reflected in explicit contracts and/or direct exchanges. Therefore, the need for a favorable public reputation to signal a company's good caretaking for primary stakeholders is probably not that important.

This is not to say that the need for such a reputation is absent altogether: after all, reputations partly reflect actual business practices (Fombrun and Shanley, 1990). Moreover, reputations are important to attract new primary stakeholders - new clients, employees, shareholders, distributors, and suppliers. However, management may not need to invest that much in explicitly influencing the formation of a public reputation to maintain profitable exchange relationships with primary stakeholders. Also, since the primary stakeholder has more information than the secondary stakeholder about the extent to which the company meets its demands, symbolic management is less salient. Consequently, we suggest

Hypothesis 1a Corporate social performance dimensions that concern primary stakeholders are unrelated to firm financial performance.

Corporations' dealings with secondary stakeholders are primarily aiming at gaining or maintaining legitimacy. In this context, it is argued that secondary stakeholders are capable of affecting the course of a business in the long run: "[ $t$ ]hough the long run may require decades, or even centuries in some instances, history seems to confirm that society ultimately acts to reduce the power of those who have not used it responsibly" (Davis, 1973: 314). Interest groups can - in the end - influence customers' buying decisions or the attractiveness of a corporation to prospective employees or investors. However, contrary to primary stakeholders, the implicit exchange relationship of a corporation with its secondary stakeholders is not likely to be subject to explicit contracts or direct exchanges. Because the firm does not depend on the secondary stakeholder and has sufficient power to reduce the effect of their social demands on the firm, the demands posed by the secondary stakeholders are not absorped by the firm.

Therefore, the corporation will invest in what Godfrey (2005) calls reputational moral capital. In dealing with the secondary stakeholders' demands, reputation is thus not only the unintended consequence or accounted-for by-product of managerial activities, but is also a purposeful instrument that can be effectively and strategically used to further corporate goals. For instance, a firm may decide to invest in schools in the local community or in an advertising campaign emphasizing its good 
environmental policies purely for the sake of enhancing its reputation in the eyes of local citizens or environmental NGOs. In so doing, it hopes to avoid, e.g., legal procedures by local citizens to stop a site expansion or damaging protest campaigns by an NGO like Greenpeace. There is also ample room for a company to engage in symbolic management because the secondary stakeholders are at an informational disadvantage vis-à-vis the firm. We therefore propose

Hypothesis 1b Corporate social performance dimensions that concern secondary stakeholders are related to firm financial performance.

\section{Stakeholder and prospect decision theories}

Above, we explicitly acknowledged for stakeholder heterogeneity when discussing the importance for the corporation of maintaining good relationships with different groups of stakeholders. Below, in a similar way, we will incorporate insights from prospect decision theory (Kahneman and Tversky, 1979) into stakeholder reasoning. More specifically, we will add the arguments put forward by Jawahar and McLaughlin (2001) to develop the hypothesis that the responsiveness of corporations to various stakeholders' claims will, at least in part, depend upon the way in which managers perceive the business environment. We use this insight to argue why these responses are likely to be asymmetric - i.e., why a bad CSP reputation is viewed differently than a good one.

In prospect decision theory, two features of human perception are emphasized. The first core proposition is that an investor's estimate of the psychological value of an investment is systematically different from its actual value. This difference can be attributed to the so-called reference point that individuals take into account when assessing the value of an option. A typical reference point is one's current position in the market (Jawahar and McLaughlin, 2001: 403). For example, Greve (2003) showed that firms rate of change is lower when a firm faces gains than when it faces losses. Hence, this reference point determines to what extent the (expected) outcomes are evaluated as losses or gains.

The second core proposition is that losses are weighted more heavily than equally sized gains, which implies that individuals are risk-taking in loss situations and risk-averse in gain frames. Kahneman and Tversky (1979) have shown that people are riskaverse when they have to choose between two bets on losing something (cf. insurance), whereas they are risk-taking in a situation where the bets involve an opportunity to win the same amount of money. Therefore, prospect decision theory predicts that individuals are likely to accept more risk in situations that they frame as risky. Conversely, they perceive as relatively safe those situations in which they have the probability to realize gains.

Following prospect decision theory, Jahawar and McLaughlin (2001: 403) argue that in a situation where environmental threats dominate, corporations will be more willing to follow risky strategies than in situations where environmental opportunities are dominant, in which case risk-free or certain strategies will probably be chosen. This labeling of the environment in terms of threats or opportunities can be seen as framing strategic decision making.

In the theory on corporate social performance (see, e.g., the review by Wood and Jones, 1995), indeed, a distinction has been made between positive and negative social performance. The classical example of negative CSP is the damaging reputational impact for those corporations that maintained their operations in South Africa in the apartheid period. Maintaining operations in South Africa clearly ignored the public opinion at that time. Hence, a large negative impact of this non-responsiveness, and hence bad CSP reputation, on the corporations' financial performance is to be expected. Conversely, the accommodative strategy of not having operations in South Africa is considered to be the more "normal" response. That is, the public expects the corporation to respond to its pressure by actively correcting the behavior that caused its bad CSP reputation in the first place. Consequently, accommodative strategies are expected to have a much smaller effect on CFP than comparable non-accommodative strategies.

The above example relates to the specific case of the reputational - and hence financial - effect of having business operations in controversial locations. Clearly, the above logic is specific to the CSP dimension involved. For other CSP dimensions, a positive reputation may be at stake - e.g., those relating to diversity and environmental issues. For 
example, the impact of discriminatory hiring will probably, according to our argument from prospect decision theory, have a larger impact on corporate reputation - and hence on CFP - than comparable positive responses that actively promote the creation of a diverse workforce, as the latter is more in line with the average public opinion than the former. This gives

Hypothesis 2 The effect on corporate financial performance of good corporate social performance reputation is smaller than the impact of bad corporate social performance reputation of equal magnitude.

\section{Data and method}

\section{Data sources and variable definition}

The quality of a reputation index is a direct function of the consistency of the raters and the objectivity of the rating agency. Two sources of reputation indexes have become dominant in the field: the Fortune Corporate Reputation Index and the index constructed by the Kinder, Lydenberg and Domini corporation (KLD). Of these, KLD provides the largest dataset, covering many of the underlying dimensions of corporate social performance. Contrary to Fortune's index (Fryxell and Wang, 1994), KLD passed several tests of construct validity (Sharfman, 1996). It has therefore been used as the primary data source for this study as well. Data for the period running from 1997 up to 2002 were explored to construct our independent CSP variables, and were subsequently connected with a separate database with financial and other business information that we used to calculate control and dependent (CFP) variables. With the large size of the panel, we also avoid another problem that occurs frequently in the field: too small samples make generalizations difficult (Orlitzky et al., 2003), and reduce the analyses' statistical power.

The KLD database consists of so-called qualitative and exclusionary screens. The latter assess whether a firm participates in a specific line of business that is considered socially harmful (e.g., tobacco or gambling). These screens thus only measure negative corporate social performance. In the context of our hypotheses, we must avoid such a bias. We will thus only take the qualitative screens into account, in which seven indicators (dimensions) of corporate social performance are distinguished: community, diversity, employee relations, environment, human rights, customers (in KLD terms: products), and investors (in KLD terminology: corporate governance). For each of these dimensions, a number of criteria, ranging from five to thirteen per dimension, are available on an annual basis. These measure either strengths or concerns, indicating a positive or negative reputation for corporate social responsiveness in the domain of that specific dimension.

We go about the multi-dimensionality of CSP in two ways, calculating disaggregated and aggregated (composite) measures, respectively. First, we constructed 14 disaggregated measures, two for each of KLD's CSP dimensions. We calculated the percentage of criteria that are met for each of KLD's seven CSP dimensions, treating negative and positive criteria separately. Six of these 14 variables refer to primary stakeholders (employees, customers, and investors), whereas the other eight represent secondary stakeholders (community, diversity, environment and human rights). Second, we constructed two composite CSP measures. We emphasize that these serve purely as a benchmark case against which we show that the dataset allows for cross-stakeholder heterogeneity. Since there is no study that provides objective weights to the underlying indicators of corporate social performance, we simply assume that all seven indicators are deemed equally important for a reputation of positive and negative social performance, respectively. Hence, we computed the overall mean over the seven positive indicators and over the seven negative indicators, which we coin positive and negative corporate social performance, respectively. To avoid non-normality of the distributions, the natural logarithm of all CSP variables is used.

Corporate financial performance information is obtained from Thomson Financial's Datastream. We use return on assets (ROA) and earnings per share (EPS), ROA being measured as the ratio of pre-tax profits over the value of the firm's assets. Return on assets can be considered as an efficiency measure, whereas the earnings per share indicate firm effectiveness. Both variables are accounting measures, as 
we have not included investor perception in our theory. Moreover, we feel that it is not reasonable to assume efficient stock markets in our CSP context. To that end, an individual investor making a valuation decision should attach importance not only to his private social demands upon the firm, but to those of other stakeholders as well.

To analyze the CSP-CFP nexus, we included the following control variables, drawn from the Datastream database. For one, the relative amount of debt in the firm's capital structure is taken on board. If a firm is more heavily indebted, the probability of an investor not receiving a return increases and, therefore, the required return on equity is higher. The relative amount of debt - proxied by the debt to equity ratio - is collected to account for this effect. Moreover, firm size is relevant as larger companies might well be more vulnerable to shifts in public opinion due to their larger visibility vis-à-vis smaller firms, although Orlitzky (2001) did not find a confounding effect of firm size on the relationship between investments in social performance and CFP. Firm size is measured with the natural logarithm of the number of employees. Inter-firm heterogeneity may not be taken into account sufficiently by these control variables, since data availability limited the possibility to include variables such as R\&D (McWilliams and Siegel, 2001). To cope with this problem, we used firm fixed effects instead of industry dummies, so capturing intra-industry heterogeneity as well.

\section{Method and descriptive statistics}

The database is an unbalanced panel with 734 corporations for which observations for 1-6 years are available. Although the number of cross-sections is large, our time window is rather short from an econometric point of view. We thus relied on correlation coefficients between the independent variables and up to three leads of the dependent variables to investigate the lag structure. In a very limited amount of cases, the use of concurrent measures was open to discussion. Therefore, and because reputation can be considered to be a continuously updated cumulative measure of a firm's social performance, we feel that relying on concurrent measures is justified. We included a first-order autoregressive scheme since the Durbin-Watson statistic of analyses without such a scheme falls far short of the lower bounds presented by Bhargava et al. (1982).

In Table I, we report the usual descriptives.

All correlations are fairly low, including those between our two CFP measures, which indicates that the performance yardsticks measure different aspects of financial performance. Larger firms are less profitable if profit is measured by ROA, but perform better in terms of EPS. These bivariate relationships may vanish in a multivariate setting, as is argued by Orlitzky (2001). Debt is detrimental to financial performance, whilst larger firms tend to be more heavily indebted than their smaller counterparts, maybe due to low financial performance. We should emphasize, though, that profits are pre-tax, implying that the tax shield of debt is not included. The correlation between corporate social and financial performance is low. CSP is more strongly correlated with firm size than is CFP: larger firms seem to be more involved in both positive and negative dimensions of corporate social performance. Lastly, and strikingly, positive and negative CSP are positively correlated, which further justifies our approach to enter the underlying CSP variables separately in the regression analyses. The correlation among the CSP variables and between CSP and firm size may be indicative of an information bias: regardless of a firm's reputation for social performance, it may be that some firms provide more information based on which their social performance can be rated than others. If a firm discloses both its positive and negative CSP activities, a positive correlation between the two measures may be found. If, as is likely, larger firms disclose more than smaller firms, the correlation with firm size can be explained by this bias as well.

\section{Results}

We report the results from our hierarchical regression models in Table II. The first and third column represent the benchmark case with the composite measures of CSP inserted. To reduce the asymmetry in the distribution of the error terms, two cases had to be dropped in the model for EPS. The firm fixed effects are significant in both models and the parameter estimates for the other control variables are in line with the correlation coefficients: larger firms perform better than their smaller counterparts 
TABLE I

Descriptive statistics and correlations

\begin{tabular}{|c|c|c|c|c|c|c|c|c|}
\hline \multicolumn{4}{|c|}{ Descriptives } & \multicolumn{5}{|c|}{ Correlations } \\
\hline Variable & $N$ & Mean & $\mathrm{SD}$ & 1 & 2 & 3 & 4 & 5 \\
\hline 1. Return on assets (\%) & 2409 & 0.08 & 0.14 & & & & & \\
\hline 2. Earnings per share & 2356 & 1.08 & 6.08 & 0.17 & & & & \\
\hline 3. Firm size (employees log) & 2377 & 9.90 & 1.41 & -0.19 & 0.11 & & & \\
\hline 4. Debt to equity ratio & 2401 & 0.41 & 0.40 & -0.24 & -0.03 & 0.10 & & \\
\hline 5. Positive CSP $(\log )$ & 3000 & 0.03 & 0.02 & 0.07 & 0.02 & 0.14 & -0.07 & \\
\hline 6. Negative CSP $(\log )$ & 3000 & 0.03 & 0.03 & -0.14 & -0.02 & 0.28 & 0.15 & 0.21 \\
\hline
\end{tabular}

Notes: All correlation coefficients with absolute value above 0.03 are significant at $p<0.01 ; N$ is between 2,329 and 3,000 .

TABLE II

Regression models

\begin{tabular}{|c|c|c|c|c|}
\hline & ROA 1 & ROA 2 & EPS 1 & EPS 2 \\
\hline Constant & 0.10 & 0.14 & -1.30 & -0.60 \\
\hline Firm size & 0.01 & 0.00 & $0.37 \star \star$ & $0.30^{\star}$ \\
\hline Debt to equity ratio & $-0.09 \star \star$ & $-0.09 \star \star$ & $-1.63 \star \star$ & $-1.58^{\star \star}$ \\
\hline Positive CSP (composite) & -0.07 & & 0.51 & \\
\hline Negative CSP (composite) & $-0.40 \star \star$ & & $-5.30 \star \star$ & \\
\hline Employees positive & & 0.00 & & -0.49 \\
\hline Employees negative & & $-0.16^{\star}$ & & $-2.15 \star \star$ \\
\hline Consumers positive & & -0.09 & & -0.10 \\
\hline Consumers negative & & $-0.08 \star \star$ & & $-0.85^{\star \star}$ \\
\hline Investors positive & & $0.12^{\star}$ & & $2.57+$ \\
\hline Investors negative & & $-0.06 \star \star$ & & $-1.29^{\star}$ \\
\hline Community positive & & 0.04 & & 0.75 \\
\hline Community negative & & 0.02 & & 0.23 \\
\hline Diversity positive & & -0.03 & & 0.36 \\
\hline Diversity negative & & $-0.03^{+}$ & & -0.80 \\
\hline Environment positive & & $-0.10 \star \star$ & & $-2.34 \star \star$ \\
\hline Environment negative & & -0.06 & & -0.39 \\
\hline Human rights positive & & -0.08 & & 0.45 \\
\hline Human rights negative & & -0.02 & & 1.13 \\
\hline $\operatorname{AR}(1)$ & 0.19 & 0.18 & 0.04 & 0.04 \\
\hline Number of cross-sections & 478 & 477 & 470 & 469 \\
\hline Number of observations & 1829 & 1828 & 1791 & 1790 \\
\hline$F$-value & $9.28 \star \star$ & $9.16^{\star \star}$ & $3.37 \star \star$ & $3.31 \star \star$ \\
\hline Adjusted $R^{2}$ & 0.69 & 0.69 & 0.39 & 0.39 \\
\hline
\end{tabular}

Notes: Firm-fixed effects and AR(1) scheme included, as are White cross-section standard errors and covariance; ${ }^{+} p<0.10$, $\star_{p}<0.05$, and $\star \star p<0.01$. The models denoted ' 1 ' use composite measures and serve as a benchmark case only; the models ' 2 ' use decomposed CSP measures.

if financial performance is measured by EPS. In the ROA model, there is no effect of firm size, which may be due to the dependent variable already being scaled by a measure of size (i.e., total assets). Debt 
hurts financial performance in both models. As to the CSP-variables, we observe that the coefficients are in line with expectations, although they reach statistical significance in the case of the negative measures only.

The composite measures of corporate social performance are replaced with the seven underlying dimensions in the second and fourth column of Table II. All models are, again, statistically meaningful. The two models explain a significantly larger share of the variance in financial performance (for ROA, $F=2.07$ and $p<0.05$; for EPS, $F=1.86$ and $p<0.05)$ than the models with composite measures only. Clearly, this shows that a decomposed treatment of CSP makes perfect sense, as predicted, offering more explanatory power and more substantive insight than models using composite CSP measures. The estimates for the control variables do not differ from the benchmark case.

Consider first the set of the three dimensions that refer to primary stakeholders: employees, consumers and investors. Disregarding their wishes contributes negatively to both performance measures. Moreover, the positive indicator for investor's social demands is significant in both models as well. Although the signs are in line with previous research, the results clearly reject Hypothesis 1a, which proposed that for these dimensions corporate social and financial performance are unrelated.

The community, diversity, environment and human rights dimensions represent the interests of secondary stakeholders. It is immediately apparent that the results lead to a rejection of Hypothesis $1 \mathrm{~b}$ as well, in which we argued that the four dimensions would be related to CFP. Only two dimensions are related to ROA, the negative diversity measure even at a marginally acceptable significance level. The other dimension, measuring a firm's reputation for good environmental performance, is related to EPS as well. All other hypothesized relationships turn out to be insignificant.

Strikingly, the environmental performance variable is negatively related to both CFP measures. Apparently, a good reputation for being concerned with the environment, leads to real monetary losses. One possible explanation for this finding results from the fact that of all secondary stakeholder issues we included, the environment is beyond doubt the area in which regulation has been developed the most. It may thus be that stakeholders value the environment beyond the economically efficient level. Consequently, attaining a positive reputation requires investments up to a point where the marginal returns do not outweigh the marginal costs anymore.

Our Hypothesis 2 receives strong support from the data. We argued that an effect of negative corporate social performance on financial performance is much stronger than an effect of positive corporate social performance. Indeed, the $t$-tests show that positive social performance does not have a demonstrable effect on financial performance for five out of our seven dimensions. For a negative reputation on these dimensions, four (ROA) versus three (EPS) out of these dimensions reach statistical significance. If we accept that there is no demonstrable relationship between meeting secondary stakeholders' demands and financial performance, as our results and those of Hillman and Keim (2001) suggest, our argument receives even stronger support. For primary stakeholders, all negative dimensions reach statistical significance, all being substantively meaningful. As an example, not meeting consumer demands brings earnings per share down from $\$ 1.06$ to $\$ 0.21$ for the average firm, and return on assets from $8 \%$ to $0 \%$. Two out of three positive reputation variables are insignificant, and the third only reaches marginal significance in the EPS model and acceptable significance in the ROA model. This dimension, meeting investor demands, does have a substantial effect that outweighs the effect of a negative reputation. Overall, we find strong support for Hypothesis 2, especially in the case of primary stakeholders.

\section{Conclusion and appraisal}

In this paper, we consider two theoretical extensions to the relationship between corporate social and financial performance, and provide preliminary evidence on the validity of these extensions for two accounting performance measures. First, at the interface of resource dependence and stakeholder management theories, we claim that the relationship between CSP reputation and CFP - if any - depends on the nature of the relationship between the stakeholder and the firm, distinguishing primary (or private) from secondary (or public) stakeholder 
groups. Second, we draw from prospect decision theory to justify our claim that the impact of negative versus positive CSP is asymmetric: that is, the negative impact of bad CSP on CFP is expected to be larger than the positive effect of good CSP, due to asymmetry with which individuals tend to assess gains and losses. In line with the above, we argue that composite measures of social performance at the corporate level, which average out the impact of different stakeholder groups, are too crude to fully describe an alleged relationship between CSP and CFP.

Indeed, the fine-grained analyses with the seven underlying CSP dimensions reveal many more and more interesting results. We conclude from our analyses that a complex relationship between corporate social and financial performance is present, as we expected, albeit sometimes different from what we hypothesized. This may not come as a surprise, as most of our expectations were based on earlier work using composite CSP measures. So, our initial hypotheses must be regarded as firstguess conjectures. However, using the findings reported above, we are now in the position to develop second guesses.

Our first key argument was that the fundamental difference between primary and secondary stakeholders - the degree to which both parties in a stakeholder relationship depend on each other, and are involved in explicit contracts and/or direct exchanges - shapes the relationship between CFP and the specific dimension of CSP. More specifically, we hypothesized that for secondary stakeholders a reputation for good (bad) CSP is more relevant than it is for primary stakeholders (Hypotheses $1 \mathrm{a}$ and $\mathrm{b}$ ). After all, primary stakeholders can protect their interests much more effectively by other means, through direct bargaining and exchanges with the focal firm, than can secondary stakeholders. Overall, our series of results are not in line with this argument.

Here, we would like to suggest three possible explanations for the latter finding. First, our sample's focus on the S\&P 500 implies a size bias. For large corporations, which are much more in the public eye than their smaller counterparts, a bad or good 'secondary' corporate social performance is likely to spill over to their 'primary' CSP reputation. Second, the S\&P 500 sample is associated with an age bias as well. As will be explained below, CSP is argued to be particularly important for mature firms. Third, we also have a period bias here. Our time window covers a period in which the zeitgeist was very much in favor of CSP. This reinforces the age and size biases. Hence, it would be interesting to replicate our study for younger and smaller firms in other time periods. Moreover, apart from this empirical extension, we believe that further disaggregation of our crude primary versus secondary stakeholder groups will be fruitful theoretically. Can a similar but more fine-grained logic be applied to lower-level stakeholders such as customers, employees, governments and stakeholders?

Our second key argument involves prospect decision theory, arguing that negative CSP will be evaluated differently than positive CSP. We find strong support for this theoretical extension. Especially for primary stakeholders, the coefficients for positive social involvement do not deviate from zero, whereas negative social involvement is shown to be detrimental to our pair of accounting performance measures. Our analysis suggests some promising future research opportunities. We especially suggest to incorporate the framing of stakeholders: we primarily focused on the managers' frames. However, the stakeholders' perceptions are likely to be affected by framing effects, too, thus affecting their social demands.

We would like to conclude with two additional suggestions for future work. First, an interesting avenue for future research is to consider the moderating impact of the organizational life cycle. Jawahar and McLauglin (2001) claim that the stakeholders that really matter to an organization are different in the various stages of the life cycle. In empirical terms, this would suggest to add interactions of CSP indicators and firm age (not available in our dataset). In all likelihood, our sample is restricted to firms in the mature stage. Jawahar and McLaughlin (2001) reason that slack resources allow these firms to proactively deal with all stakeholders' desires. Our results are in line with previous research in this area, which tend to find a positive association between firm size and CSP. We cannot reproduce the finding that firm size - as measured by the number of employees - and firm profitability are positively correlated regardless of the profitability measure used. A related argument concerns Wood's (1991a, b) that corporate social performance is an instrument for organizational 
legitimacy. Due to our sampling procedure, the ultimate consequence of socially unresponsiveness - i.e., organizational decline - cannot be observed. The consideration of firms in other stages of the life cycle will provide opportunities to test this type of logic.

Second, we would like to mention the role of the characteristics of the underlying processes, and the key decision makers, in shaping the relationships between CSP and CFP. The literatures on board processes (e.g., Forbes and Miliken, 1999) and upper echelons (e.g., Hambrick and Mason, 1984) provide ample room for further theory development. Indeed, the conclusion on the sign and strength of a relationship between CSP and CFP, and their underlying dimensions and indicators, should ultimately be related to a careful analyses of the strategic processes that constitute these relationships. Currently, our paper crosses several levels of analysis. Our knowledge of the CSP-CFP nexus would be improved upon if we could open this black box. Of course, deep-level studies like these require further data collection efforts, adding more detail to what we know about CSP, CFP, and their reciprocal relationships. Further efforts along this line could ultimately lead to a more comprehensive understanding of the mechanisms that drive the payoff to corporate well-doing.

\section{References}

Bhargava, A., L. Franzini and W. Narendranathan: 1982, 'Serial Correlation and The Fixed Effects Model', Review of Economic Studies 49, 533-549.

Casciaro, T. and M. J. Piskorski: 2005, 'Power Imbalance, Mutual Dependence, and Constraint Absorption: A Closer Look at Resource Dependence Theory', Administrative Science Quarterly 50, 167-199.

Clarkson, M. B. E.: 1995, 'A Stakeholder Framework for Analyzing and Evaluating Corporate Social Performance', Academy of Management Review 20, 92-117.

Davis, K.: 1973, 'The Case for and Against Business Assumption of Social Responsibilities', Academy of Management Journal 16, 312-322.

Fombrun, C. and M. Shanley: 1990, 'What's in a Name? Reputation Building and Corporate Strategy', Academy of Management Journal 33, 233-258.

Forbes, D. P. and F. J. Miliken: 1999, 'Cognition and Corporate Governance: Understanding Boards of Directors as Strategic Decision-Making Groups', Academy of Management Review 24, 489-505.
Fryxell, G. E. and J. Wang: 1994, 'The Fortune Corporate 'Reputation' Index: Reputation for What?', Journal of Management 20, 1-14.

Godfrey, P. C.: 2005, 'The Relationship Between Corporate Philantropy and Shareholder Wealth: A Risk Management Perspective', Academy of Management Review 30, 777-798.

Greve, H. R.: 2003, Organizational Learning from Performance Feedback: A Behavioral Perspective on Innovation and Change (Cambridge University Press, Cambridge).

Hambrick, D. C. and P. A. Mason: 1984, 'Upper Echelons: The Organization as a Reflection of Its Top Managers', Academy of Management Review 9, 193-206.

Hillman, A. J. and G. D. Keim: 2001, 'Shareholder Value, Stakeholder Management, and Social Issues: What's The Bottom Line?', Strategic Management Journal 22, 125-139.

Jawahar, I. M. and G. L. McLaughlin: 2001, 'Toward a Descriptive Stakeholder Theory: An Organizational Life Cycle Approach', Academy of Management Review 26, 397-414.

Kahneman, D. and A. Tversky: 1979, 'Prospect Theory: An Analysis of Decisions Under Risk', Econometrica 47, 263-291.

Margolis, J. D. and J. P. Walsh: 2003, 'Misery Loves Companies: Rethinking Social Initiatives by Business', Administrative Science Quarterly 48, 268-305.

McWilliams, A. and D. Siegel: 2001, 'Corporate Social Responsibility: A Theory of the Firm Perspective', Academy of Management Review 26, 117-127.

Orlitzky, M.: 2001, 'Does Firm Size Confound the Relationship Between Corporate Social Performance and Firm Financial Performance?', Journal of Business Ethics 33, 167-180.

Orlitzky, M., F. L. Schmidt and S. L. Rynes: 2003, 'Corporate Social and Financial Performance: A Metaanalysis', Organization Studies 24, 403-441.

Pava, M. L. and J. Krausz: 1996, 'The Association Between Corporate Social-Responsibility and Financial Performance: The Paradox of Social Cost', Journal of Business Ethics 15, 321-357.

Pfeffer, J. and G. R. Salancik: 1978. 'The External Control of Organizations: A Resource Dependence Perspective. Reprint 2003 (Stanford University Press, Stanford).

Schmidt, F. L.: 1992, 'What Do Data Really Mean?', American Psychologist 47, 1173-1181.

Sharfman, M.: 1996, 'The Construct Validity of the Kinder, Lydenberg, \& Domini Social Performance Ratings Data', Journal of Business Ethics 15, 287-296.

Westphal, J. D. and E. J. Zajac: 1994, 'Substance and Symbolism in CEOs' Long-Term Incentive Plans', Administrative Science Quarterly 39, 367-390.

Westphal, J. D. and E. J. Zajac: 1998, 'The Symbolic Management of Stockholders: Corporate Governance 
Reforms and Shareholder Reactions', Administrative Science Quarterly 43, 127-153.

Wood, D. J.: 1991a, 'Corporate Social Performance Revisited', Academy of Management Review 16, 691-718.

Wood, D. J.: 1991b, 'Social Issues in Management: Theory and Research in Corporate Social Performance', Journal of Management 17, 383-406.

Wood, D. J. and R. E. Jones: 1995, 'Stakeholder Mismatching: A Theoretical Problem in Empirical Research on Corporate Social Performance', International Journal of Organizational Analysis 3, 229-267.

Zajac, E. J. and J. D. Westphal: 1995, 'Accounting for The Explanations of CEO Compensation: Substance and symbolism', Administrative Science Quarterly 40, 283-308.
Gerwin Van der Laan and Hans Van Ees International Economics and Business,

University of Groningen, P.O. Box 800 Groningen, $9900 \mathrm{AV}$, The Netherlands E-mail:gerwin.van.der.laan@rug.nl

Arjen Van Witteloostuijn Department of Management,

University of Antwerpen,

Kipdorp 61, 2000, Antwerpen, Belgium 